\title{
HIDROLISADOS PROTÉICOS DE ARROZ COM BAIXO TEOR DE FENILALANINA, OBTIDOS PELA AÇÃO DA COROLASE PP E USO DO CARVÃO ÁTIVADO ${ }^{1}$
}

\author{
Rice protein hydrolysates with low phenylalanine content, prepared by the action \\ of corolase PP and the use of activated carbon
}

\author{
Carolina Schaper Bizzotto ${ }^{2}$, Michely Capobiango², Eliza Augusta Rolim Biasutti²,Viviane Dias Medeiros Silva², \\ Roberto Gonçalves Junqueira², Marialice Pinto Coelho Silvestre ${ }^{2}$
}

\begin{abstract}
RESUMO
A partir do extrato protéico obtido em meio alcalino, empregou-se a corolase PP no preparo de seis hidrolisados enzimáticos de arroz, visando o desenvolvimento de formulações dietéticas para fenilcetonúricos. O procedimento de passagem por coluna contendo carvão ativado foi utilizado na remoção de fenilalanina (Phe) dos hidrolisados. $\mathrm{O}$ teor de Phe nos extratos protéicos de arroz e seus hidrolisados, após tratamento com carvão, foi determinado por espectrofotometria derivada segunda. O teor final de fenilalanina nos hidrolisados variou de 0,39 a $68,34 \mathrm{mg} 100 \mathrm{~g}^{-1}$, o que corresponde a uma remoção de 84 a $100 \%$. A distribuição dos peptídeos nas amostras, de acordo com o tamanho da cadeia, foi estudada como um dos critérios para a avaliação da qualidade nutricional dos hidrolisados. O fracionamento dos peptídeos foi realizado por CLAE de exclusão molecular e, para a quantificação empregou-se o método rápido da área corrigida da fração. Os resultados indicaram que o maior teor de oligopeptídeos foi obtido quando se empregou a corolase PP em uma relação E:S de 1\%, e uma concentração protéica inicial de $1,56 \mathrm{~g} 100 \mathrm{~mL}^{-1}$.
\end{abstract}

Termos para indexação: Hidrólise enzimática, remoção de fenilalanina, suplemento dietético.

\begin{abstract}
Starting with alkaline protein extract, the Corolase PP was used for preparing six enzymatic rice hydrolysates, with the aim of producing dietary formulations for phenylketonuria treatment. A column containing activated pure charcoal was used for removing phenylalanine (Phe). The Phe contents of rice protein extract and hydrolysates were determined by second derivative spectrophotometry. The final Phe content of the hydrolysates varied from 0.39 to $68.34 \mathrm{mg} 100 \mathrm{~g} \mathrm{~g}^{-1}$, corresponding to removal levels from $84 \%$ to $100 \%$. The distribution of peptides according to their size was used as an approach for the nutritional evaluation of the hydrolysates. The fractionation of peptides was performed by size-exclusion HPLC, and the rapid correct fraction area method was used for the their quantification. The results indicated that the higher oligopeptide content was obtained when corolase PP was used with an

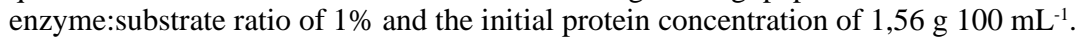

Index terms: Enzymatic hydrolysis, phenylalanine removal, dietary supplement.

(Recebido para publicação em 2 de junho de 2005 e aprovado em 10 de novembro de 2005)

\section{INTRODUÇÃO}

Os hidrolisados protéicos apresentam diversas vantagens funcionais e nutricionais em relação às proteínas integrais. Em geral, esses preparados enzimáticos possuem menor imunogenicidade que a de proteínas e de peptídeos de elevado peso molecular (TAKASE et al., 1979). Além disso, vários estudos demonstram que fórmulas contendo um elevado teor de oligopeptídeos são utilizadas mais efetivamente quando comparadas a uma mistura equivalente de aminoácidos livres, apresentando assim um maior valor nutritivo (FrÆKJAER, 1994; GONZÁLEZTELLO et al., 1994).

Os hidrolisados protéicos são muito utilizados, em diversos países, na alimentação de pessoas que apresentam dificuldades na absorção de proteínas, como idosos, crianças com diarréia e portadores de fibrose cística (AUBES-DUFAU et al., 1995), indivíduos com necessidade aumentada de proteínas, como os atletas (FrÆKJAER, 1994) e na dieta de pacientes que apresentam desordens no metabolismo de aminoácidos, como a fenilcetonúria (CLEMENTE, 2000). Esta é uma doença autossômica recessiva caracterizada pela ausência ou deficiência da atividade da enzima hepática fenilalanina-hidroxilase, que converte a fenilalanina (Phe) em tirosina (LOPEZBAJONERO et al., 1991; OUTINEN et al., 1996; SHIMAMURA et al., 1999).

O tratamento da fenilcetonúria é essencialmente dietético e baseia-se na restrição da ingestão de Phe, de forma que o paciente deve evitar o consumo de alimentos

'Extraído da dissertação do primeiro autor para a obtenção do título de Mestre em Ciência de Alimentos na Universidade Federal de Minas Gerais/UFMG. 2Departamento de Alimentos, Faculdade de Farmácia, Universidade Federal de Minas Gerais/UFMG - Av. Antônio Carlos - 6627 - $31270-901$ Belo Horizonte, MG - malice@farmacia.ufmg.br 
ricos em proteínas. Torna-se necessário, portanto, o uso de formulações constituídas por misturas de aminoácidos livres ou hidrolisados protéicos, isentos ou com baixos teores de Phe, de forma a suprir as necessidades protéicas e garantir o crescimento e desenvolvimento normais destes indivíduos (MIRA \& MÁRQUEZ, 2000).

Os hidrolisados protéicos com teor reduzido de Phe são preparados a partir da ação de uma protease, que expõe a Phe, permitindo sua remoção por um meio adsorvente (LOPES-BAJONERO et al., 1991; OUTINEN et al., 1996; SHIMAMURA et al., 1999). Nesse trabalho, utilizou-se a corolase PP, um complexo enzimático proteolítico obtido do pâncreas suíno, que além de possuir atividade de endoproteinase, apresenta também amino- e carboxipeptidases (AB ENZYMES, 2001). A quantificação do teor de Phe residual pode ser feita por diferentes métodos, destacando-se a espectrofotometria derivada segunda (EDS) (GRANT \& BHATTACHARYYA, 1985; ICHIKAWA \& TERADA, 1977, 1979, 1981a, b; ROJAS et al., 1998). A EDS tem sido utilizada com êxito em diversos trabalhos. (DELVIVO et al., 2004; LOPES et al., 2004; MARCO, 2004; MORAIS et al., 2005; SILVA, 2004; SILVESTRE et al., 1993; SOARES et al., 2004).

Levando-se em conta a posição relevante que o arroz ocupa na dieta do brasileiro, seria interessante a sua utilização como matéria-prima para o desenvolvimento de hidrolisados com baixo teor de Phe. Cerca de 12,3\% da energia e 9,2\% da proteína ingeridos na dieta média do brasileiro são fornecidos pelo arroz e o consumo per capita de arroz no Brasil foi de $84,8 \mathrm{~kg} /$ habitante no ano de 2001 (FAO, 2004; IRRI, 2001).

A cromatografia líquida de alta eficiência de exclusão molecular (SE-HPLC) tem sido utilizada com êxito na caracterização de perfil peptídico de hidrolisados. (CARREIRA et al., 2002; DELVIVO et al., 2004; LOPES et al., 2004; MARCO, 2004; MORATO et al., 2000; MORAIS et al., 2005; SILVA, 2004; SOARES et al., 2004). É interessante que se conheça o perfil peptídico de hidrolisados protéicos para uso em dietas especiais, pois, segundo González-Tello (1994), eles devem apresentar as seguintes características: alto teor de di- e tri-peptídeos, massa molecular média de 500 Da e não conter peptídeos maiores que 1000 Da.

Objetivou-se com este trabalho otimizar a extração da proteína do arroz, avaliar a utilização do carvão ativado na remoção de Phe de hidrolisados protéicos de arroz, obtidos pela ação da corolase PP, e caracterizar o perfil peptídico destes hidrolisados, visando o desenvolvimento de formulações dietéticas para fenilcetonúricos.

\section{MATERIAL E MÉTODOS}

\section{Material}

A corolase PP foi adquirida da AB Enzymes (Darmstadt, Alemanha) e os aminoácidos L-fenilalanina, L-tirosina e Ltriptofano foram adquiridos da Sigma-Aldrich (St. Louis, MO, USA). O carvão ativado (granulado n.119, 20 a 50 mesh série Tyler) foi adquirido da Carbomafra S.A. (Curitiba, PR). O arroz polido tipo 1 foi obtido no comércio de Belo Horizonte, MG. Os demais reagentes foram de grau analítico.

No sistema de cromatografia líquida de alta eficiência (HPLC), para o fracionamento dos hidrolisados protéicos, foi utilizada uma coluna cromatográfica PHEA [poli-(2-hidroxietilaspartamida)-silica], 250 x 9,4 mm, $5 \mathrm{~mm}$ e $200 \AA$ (PolylC, Columbia, MD). Uma bomba isocrática e um detector espectrofotométrico em UV-VIS (série HP 1100, Waldbronn, Alemanha), acoplado a um computador com software HP Chemstation (Avondale, EUA). O ácido fórmico foi obtido da Merck (Darmstadt, Alemanha). A água utilizada no cromatógrafo foi purificada em Sistema de Purificação de Água Aries (Vaponics, EUA). As membranas de celulose usadas na filtração das amostras $(0,20 \mathrm{~mm}) \mathrm{e}$ dos solventes $(0,45 \mathrm{~mm})$ foram adquiridas da Sartorius (Goettingen, Alemanha).

\section{Métodos}

\section{Extração das proteínas do arroz}

Foi realizada uma extração alcalina para obtenção do extrato protéico bruto de arroz, utilizando-se o método citado por Connor et al. (1976), com algumas modificações. A $80 \mathrm{~g}$ de arroz moído, foram adicionados $400 \mathrm{~mL}$ de água destilada e quantidade suficiente de uma solução de hidróxido de sódio $3 \mathrm{~mol} / \mathrm{L}$, até atingir o $\mathrm{pH}=12,0$. A mistura foi agitada por 60 minutos em agitador magnético e, então, foi centrifugada em velocidade de $425 \mathrm{x}$ g por 10 minutos. A fração líquida $(\mathrm{Sn} 1)$ foi separada e o resíduo sólido foi lavado com uma solução de hidróxido de sódio $0,1 \mathrm{~mol} / \mathrm{L}$. A mistura foi novamente centrifugada por 5 minutos. A fração líquida obtida ( $\mathrm{Sn2}$ ) foi adicionada ao $\mathrm{Sn} 1$, e a fração sólida foi lavada duas vezes com água destilada, recolhendo-se sempre a fração líquida e adicionando-a à fração Sn1. A fração líquida foi, então, neutralizada com solução de ácido clorídrico $3 \mathrm{~mol} / \mathrm{L}$, congelada e liofilizada (Liofilizador Freezone, modelo 77500, Labconco, Kansas City, MI, USA). A fração líquida, após liofilização, foi denominada Extrato Protéico de Arroz (EPA). O teor de proteína do EPA obtido foi determinado pelo método de micro-Kjeldahl $n^{\circ} 960.52$. 


\section{Preparo dos hidrolisados protéicos de arroz}

Foram preparados seis hidrolisados enzimáticos, utilizando-se a corolase PP. A cada uma das soluções de EPA em água (concentrações de 1 a $3 \mathrm{~g} / 100 \mathrm{~mL}$ ), adicionou-se benzoato de sódio $(0,1 \% \mathrm{p} / \mathrm{v})$ e ajustou-se o pH para 9,0, que se manteve inalterado até o final da reação. As soluções foram levadas a banho-maria a $25^{\circ} \mathrm{C}$ e adicionou-se a enzima em quantidade suficiente para se obter a relação enzima:substrato desejada (E:S). Após 5 horas de hidrólise, a reação foi interrompida pela adição de ácido fosfórico PA (min. 85\%), suficiente para reduzir o pH para 3. Posteriormente, os hidrolisados foram congelados e liofilizados.

\section{Remoção de Phe dos hidrolisados protéicos de arroz}

A Phe foi removida dos hidrolisados protéicos de arroz pela utilização do carvão ativado, como meio adsorvente. Foi utilizado o procedimento de passagem por coluna, desenvolvido por Soares et al. (2004). O carvão foi hidratado com água purificada por 10 minutos e, em seguida, colocado em seringa descartável de $20 \mathrm{~mL}$, contendo filtro de nylon com lã de vidro. Preparou-se uma solução de hidrolisado $(0,8 \mathrm{~g} / 100 \mathrm{~mL})$, que foi aplicada à coluna, sob pressão (compressor Diapump, Fanem, mod. 089-A, série BE11778, São Paulo, SP), recolhendo-se o eluato.

\section{Avaliação da remoção de Phe}

A avaliação da eficiência de remoção de Phe pelo carvão ativado foi realizada pela medida do teor de Phe livre, no EPA e seus hidrolisados (após tratamento com carvão), empregando-se a técnica desenvolvida no mesmo laboratório em que o presente estudo foi realizado (LOPES et al., 2004), baseada na Espectrofotometria Derivada Segunda (EDS). Desta forma, as soluções de hidrolisados $(0,8 \mathrm{~g} / 100 \mathrm{~mL}$ de água purificada), previamente submetidas ao tratamento com carvão ativado, e a solução de EPA ( 0,2 $\mathrm{g} / 100 \mathrm{~g}$ de água purificada), foram colocadas em tubos especiais de hidrólise e evaporadas em Centrivap (Labconco, EUA) até resíduo. Posteriormente, foi realizada a hidrólise ácida, adicionando-se $\mathrm{HCl} 5,7 \mathrm{~mol} / \mathrm{L}$, e colocando-se em estufa a $110^{\circ} \mathrm{C}$ por $24 \mathrm{~h}$, para liberação da Phe. Após este tempo, as amostras foram reconstituídas com água purificada para $10 \mathrm{~mL}$, filtradas em papel de filtro qualitativo e o pH foi ajustado para 6,0, com solução de fosfato de sódio bibásico 1,0 mol/L.

Para a determinação do teor de Phe pela EDS, preparou-se, inicialmente, uma curva-padrão de Phe na presença de tirosina (Tyr) e triptofano (Trp). Para tal, soluções estoque dos aminoácidos aromáticos, Phe, Tyr e Trp, foram preparadas em tampão fosfato de sódio $0,01 \mathrm{~mol} / \mathrm{L}(\mathrm{pH} 6,0)$, nas concentrações de $6,05 \times 10^{-4}$ $\mathrm{mol} / \mathrm{L} ; 5,52 \times 10^{-4} \mathrm{~mol} / \mathrm{L}$ e $4,90 \times 10^{-4} \mathrm{~mol} / \mathrm{L}$, respectivamente. A partir dessas soluções, foram preparadas, por diluições sucessivas, soluções contendo Phe em concentrações variando de 0,067 a $2,018 \times 10^{-4} \mathrm{~mol} / \mathrm{L}$. Estas soluções foram, então, submetidas às leituras de absorvância na faixa de 250 a $280 \mathrm{~nm}$ em espectrofotômetro (CECIL modelo CE2041, Buck Scientific, Inglaterra). Os espectros de derivada segunda foram traçados em computador com o software GRAMS-UV (Galactic Industries Corporation, Salem, $\mathrm{NH}, \mathrm{EUA}$ ), acoplado ao espectrofotômetro. Dos quatro picos negativos obtidos, foram utilizados os valores de área e altura dos $3^{\circ}$ e $4^{\circ}$ picos para traçar a curva padrão em função da concentração de Phe.

Para medir o teor de Phe livre nas amostras, foram traçados os espectros das soluções obtidas após a hidrólise ácida na mesma faixa de comprimento de onda da curva padrão. Posteriormente, traçaram-se os espectros de derivada segunda, e levaram-se à curva padrão os valores de área ou altura dos picos negativos escolhidos acima, para encontrar a concentração de Phe.

\section{Caracterização do perfil peptídico dos hidrolisados protéicos de arroz}

A caracterização do perfil peptídico dos hidrolisados consistiu no fracionamento dos peptídeos, de acordo com o tamanho da cadeia, e sua posterior quantificação.

O fracionamento dos peptídeos foi realizado por HPLC de exclusão molecular em coluna PHEA, conforme descrito por Silvestre et al. (1994a). As amostras foram dissolvidas a uma concentração de $1 \mathrm{~g} / 100 \mathrm{~mL}$ em uma solução de ácido fórmico $0,05 \mathrm{~mol} / \mathrm{L}$ (pH 2,5) e submetidas à cromatografia à temperatura ambiente, sob condições isocráticas, a um fluxo de $0,5 \mathrm{~mL} / \mathrm{min}$, durante 35 minutos. A fase móvel foi filtrada, através de membrana de 0,45 $\mathrm{mm}$, e desgaseificada imediatamente antes do uso. As frações foram separadas de acordo com o tempo de eluição, sendo F1, de 13,5 a 18,0 min (peptídeos grandes, com mais de 7 aminoácidos); F2, de 18,0 a 21,5 min (peptídeos médios, entre 4 e 7 aminoácidos); F3, de 21,5 a 22,5 min (di- e tri-peptídeos); e F4, de 22,5 a 32,0 min (aminoácidos livres).

O método rápido da Área Corrigida da fração (ACF), desenvolvido por Silvestre et al. (1994b), foi utilizado para quantificar os peptídeos e aminoácidos livres presentes nos hidrolisados de proteína de arroz. Após a 
multidetecção das frações a 230, 280 e $300 \mathrm{~nm}$, para se eliminar a interferência da absorção dos aminoácidos aromáticos, calcula-se a ACF. Esta, por sua vez, é levada a uma curva padrão, para se encontrar a quantidade de peptídeos de cada fração, preparada como descrito em outros trabalhos (LOPES et al., 2004; MORATO et al., 2000; SILVESTRE et al., 1994b).

\section{Análise estatística}

Todas as determinações foram realizadas em triplicata. Utilizaram-se a Análise de Variância (ANOVA fator único) e o Teste de Duncan a 5\% de probabilidade, para comparar o teor final de Phe no EPA e nos hidrolisados, após tratamento com carvão ativado. Para se comparar a quantidade dos peptídeos e aminoácidos livres das frações cromatográficas foi adotado um delineamento fatorial $2 \times 4$, sendo dois hidrolisados e quatro frações, em três repetições totalizando 24 parcelas. As médias foram comparadas pelo Teste de Duncan a 5\% de probabilidade. As curvas padrão foram obtidas por análise de regressão (PIMENTEL-GOMES, 2000).

\section{RESULTADOS E DISCUSSÃO}

\section{Espectrofotometria derivada segunda: curva padrão e} espectros

A curva padrão de Phe escolhida, obtida por meio da EDS, refere-se à que foi traçada empregando-se a área do terceiro pico, pois esta apresentou o maior coeficiente de determinação $\left(\mathrm{R}^{2}\right)$ quando comparada à altura. Constatou-se, também, que a regressão linear para Phe foi significativa $(\mathrm{p}<0,01)$. As equações da reta e os coeficientes de determinação obtidos foram os seguintes: $y=3,0077 x+0,7587$ e $R^{2}=0,9576$. Outros autores também relataram resultados semelhantes ao relacionarem a área e/ ou altura do pico de absorção de Phe, em presença de Tyr e Trp, com a concentração de Phe (ICHIKAWA \& TERADA, 1977; ZHAO et al., 1996). O mesmo foi descrito em trabalhos anteriores desenvolvidos no mesmo laboratório do presente trabalho (DELVIVO et al., 2004; LOPES et al., 2004; MARCO, 2004; MORAIS et al., 2005; SILVA, 2004; SOARES et al., 2004). No entanto, alguns autores encontraram números de picos negativos diferentes aos deste estudo, no espectro da Phe (ICHIKAWA \& TERADA, 1977; MICLO et al., 1995). Segundo Levillain \& Fompeydie (1986), esta variação no espectro da Phe poderia estar associada às diferenças nas formas utilizadas do aminoácido padrão (livre ou N-acetil-éster), na aparelhagem empregada, em especial o espectrofotômetro e o software, como também no tipo de solvente e os valores de $\mathrm{pH}$.

\section{Eficiência da remoção de Phe}

Pode-se observar, na Tabela 1, que o uso do carvão ativado foi eficiente na remoção de Phe de hidrolisados protéicos de arroz obtidos pela ação da corolase PP. O percentual de remoção variou de 89 a $100 \%$, e o teor final de Phe nos hidrolisados foi de 0,39 a $68,34 \mathrm{mg}$ de Phe/100 g de hidrolisado.

O teor inicial de Phe no EPA era de $611,9 \mathrm{mg}$ de Phe/ $100 \mathrm{~g}$ de extrato. Os resultados foram apresentados em termos de teor final de Phe (em mg de Phe/100 g de hidrolisado) e porcentagem de remoção de Phe, sendo a primeira forma a mais indicada para os cálculos de adequação das prescrições dietéticas de substitutos protéicos destinados a fenilcetonúricos, além de atender a regulamentação técnica que normatiza a rotulagem nutricional de alimentos (ANVISA, 2003).

Acrescenta-se, ainda, que, numa formulação dietética para fenilcetonúricos contendo apenas hidrolisado protéico de arroz, o teor de Phe por $100 \mathrm{~g}$ de hidrolisado variaria de 0,39 a 68,34 $\mathrm{mg}$, bem abaixo do limite máximo permitido pela legislação brasileira (BRASIL, 2002), que é de $0,1 \mathrm{~g}$ de Phe por $100 \mathrm{~g}$ de produto, em formulações para fenilcetonúricos, mesmo empregando o hidrolisado protéico com menor remoção de Phe.

Resultados semelhantes (75 a 99\% de remoção) foram obtidos no mesmo laboratório onde o presente trabalho foi realizado, utilizando-se carvão ativado para remover a Phe de hidrolisados enzimáticos de leite em pó desnatado (LOPES et al., 2004; SOARES et al., 2004) e de soro de leite em pó (DELVIVO et al., 2004; MARCO, 2004; SILVA, 2004). Outros autores também relataram resultados de remoção de Phe próximos aos obtidos neste trabalho, utilizando carvão ativado. Assim, LopezBajonero et al. (1991) conseguiram remover $92 \%$ da Phe de hidrolisados protéicos de leite em pó desnatado e caseinato de sódio obtidos pela ação da papaína e de uma protease microbiana. Moszczynsky \& Idziac (1993), empregaram uma mistura de três enzimas (carboxipeptidase A, aminopeptidase e quimotripsina) na hidrólise de caseína, obtendo, após tratamento com carvão, cerca de $90 \%$ de remoção de Phe. Níveis de remoção de $97 \%$ foram relatados por Kitagawa et al. (1987) em hidrolisados de proteínas do soro de leite obtidos pela ação da actinase.

Não foram encontrados na literatura trabalhos utilizando a proteína do arroz na produção de hidrolisados com baixo teor de Phe. 
TABELA 1 - Percentual de remoção e teor final de Phe dos hidrolisados protéicos de arroz, obtidos pela ação da Corolase PP.

\begin{tabular}{|c|c|c|c|c|}
\hline \multicolumn{3}{|c|}{ Hidrolisados } & \multirow[b]{2}{*}{$\begin{array}{c}\text { Teor final de Phe } \\
\text { (mg Phe/100g de hidrolisado) }\end{array}$} & \multirow[b]{2}{*}{$\begin{array}{c}\text { Remoção de Phe } \\
(\%)\end{array}$} \\
\hline Amostra & $\begin{array}{l}\text { Concentração de } \\
\text { EPA (g/100 mL) }\end{array}$ & E:S (\%) & & \\
\hline H1 & 1 & 1 & $1,57 \pm 12,01^{b}$ & 100 \\
\hline $\mathrm{H} 2$ & 1 & 2 & $1,77 \pm 10,67^{\mathrm{b}}$ & 100 \\
\hline H3 & 2 & 1 & $5,26 \pm 16,22^{b}$ & 99 \\
\hline $\mathrm{H} 4$ & 2 & 2 & $0,39 \pm 11,68^{b}$ & 100 \\
\hline H5 & 3 & 1 & $68,05 \pm 13,46^{\mathrm{a}}$ & 89 \\
\hline H6 & 3 & 2 & $68,34 \pm 17,81^{\mathrm{a}}$ & 89 \\
\hline
\end{tabular}

EPA = Extrato Protéico de Arroz. E:S = relação enzima:substrato. Teor final de Phe = teor de Phe dos hidrolisados, após tratamento com carvão ativado e hidrólise ácida. Os resultados representam a média das triplicatas e seu desvio padrão. Médias indicadas por letras iguais não diferem entre si a 5\% de probabilidade pelo teste de Duncan.

Uma das grandes vantagens desse trabalho em relação aos de outros autores, refere-se à possível otimização do processo dos pontos de vista tecnológico e econômico, uma vez que resultados favoráveis à remoção de Phe foram obtidos com o emprego de apenas uma enzima, com tempo inferior e menores quantidades de carvão e relação E:S.

Efeito dos parâmetros hidrolíticos sobre a remoção de Phe

Foram analisados os seguintes parâmetros: concentração inicial de extrato protéico e relação enzima:substrato.

Comparando-se os resultados obtidos para os hidrolisados H1, H3 e H5, ou H2, H4 e H6 (Tabela 1), pode-se avaliar o efeito da concentração do substrato protéico (EPA). Assim, observa-se que o aumento da concentração de EPA de $1 \mathrm{~g} / 100 \mathrm{~mL}(0,78 \mathrm{~g}$ de proteína/ $100 \mathrm{~mL}-\mathrm{H} 1$ e H2) para $2 \mathrm{~g} / 100 \mathrm{~mL}$ (1,56 g de proteína/100 $\mathrm{mL}-\mathrm{H} 3$ e H4) não teve efeito na remoção de Phe. A elevação desta concentração inicial para 3 g/100 mL (2,34 g de proteína/100 mL - H5 e H6), porém, foi prejudicial, uma vez que levou a um aumento no teor final de Phe. Esperava-se que esse aumento na concentração protéica levasse a uma maior probabilidade da enzima entrar em contato com o substrato, levando a uma maior exposição da Phe e, conseqüentemente, uma maior remoção deste aminoácido. No entanto, o efeito da hidrólise enzimática na remoção de Phe é muito complexo, como será visto adiante.

$\mathrm{Na}$ avaliação da influência da relação $\mathrm{E}: \mathrm{S}$, foram comparados os resultados obtidos para os hidrolisados H1 com H2, H3 com H4 e H5 com H6 (Tabela 1). Observa-se que, nos três casos, o aumento de duas vezes na relação E:S não teve efeito para a remoção de Phe.

O efeito da relação E:S sobre a remoção de Phe foi avaliado em vários trabalhos. Assim, dependendo das condições hidrolíticas empregadas, o aumento na relação E:S foi prejudicial para a remoção de Phe (LOPES et al., 2004; DELVIVO et al., 2004), benéfico (DELVIVO et al., 2004; SILVA, 2004), ou sem efeito (DELVIVO et al., 2004; MARCO, 2004; SOARES et al., 2004). Apesar de se esperar que o aumento da relação E:S levaria sempre a um maior grau de hidrólise e, conseqüentemente, a uma liberação de Phe mais pronunciada, facilitando a sua remoção, o conjunto de todos esses resultados indica que, na prática, esse procedimento é mais complexo do que o teoricamente esperado, e o efeito da relação E:S sobre a remoção de Phe depende de diversos fatores, tais como o tipo e concentração de enzima e de substrato e a temperatura da reação hidrolítica.

\section{Caracterização do perfil peptídico dos hidrolisados protéicos de arroz}

Os hidrolisados $\mathrm{H} 3$ e $\mathrm{H} 4$ foram analisados quanto à distribuição de peptídeos e aminoácidos livres, pois, entre os que apresentaram o menor teor final de Phe, estes utilizaram maior concentração protéica inicial $(1,56 \mathrm{~g} / 100 \mathrm{~mL})$, o que tornaria a etapa de secagem mais econômica, quando do seu preparo em larga escala. A título de exemplo, está apresentado na Figura 1 o perfil cromatográfico do hidrolisado $\mathrm{H} 4$.

Os teores de peptídeos e de aminoácidos livres nas frações cromatográficas estão apresentados na Tabela 2. 
Observa-se que, do ponto de vista nutricional, o perfil peptídico do hidrolisado $\mathrm{H} 3$ foi superior ao do $\mathrm{H} 4$, por ter apresentado maior teor de oligopeptídeos (F2 + F3 $=66 \%$ e $58 \%$, respectivamente) e menor teor de grandes peptídeos (F1 $=15 \%$ e $20 \%$, respectivamente $)$ e de aminoácidos livres ( $\mathrm{F} 4=20 \%$ e $22 \%$, respectivamente). Estes resultados indicam, ainda, que o aumento da E:S de
$1 \%(\mathrm{H} 3)$ para $2 \%(\mathrm{H} 4)$ foi prejudicial para o perfil peptídico. Portanto, este procedimento (duplicação da $\mathrm{E}: \mathrm{S}$ ) não apresentou qualquer vantagem para os hidrolisados protéicos, além de ser pouco viável economicamente. Ressalta-se, ainda, que não foram encontrados na literatura dados sobre o perfil peptídico de hidrolisados protéicos de arroz.

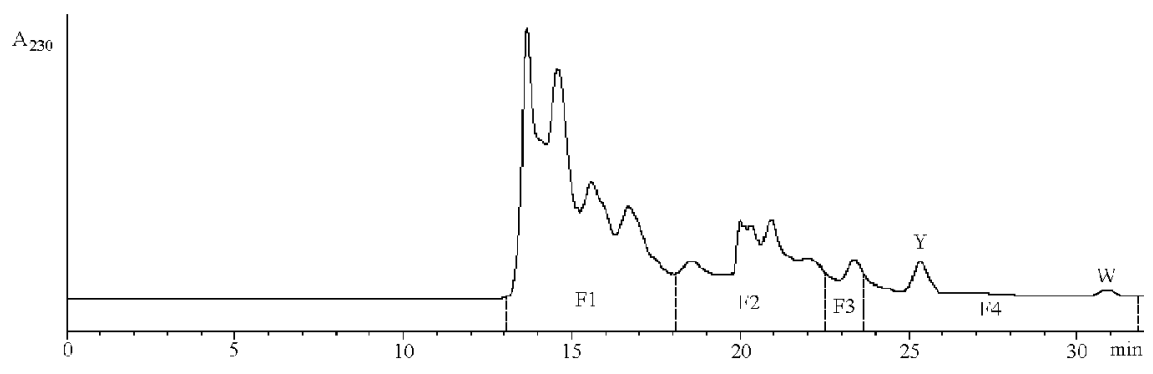

Perfil cromatográfico do hidrolisado H4 a $230 \mathrm{~nm}$. F1: grandes peptídeos (> 7 resíduos de aminoácidos); F2: médios peptídeos (4 a 7 resíduos de aminoáciods); F3: di-e tripeptídeos; F4: aminoácidos livres. Y = pico da tirosina, $\mathrm{W}=$ pico do triptofano.

FIGURA 1 - Perfil cromatográfico do hidrolisado protéico de arroz.

TABELA 2 - Teores de peptídeos e de aminoácidos livres das frações cromatográficas dos hidrolisados protéicos de arroz.

\begin{tabular}{lcc}
\hline & \multicolumn{2}{c}{ Hidrolisados } \\
\cline { 2 - 3 } Frações cromatográficas & H3 & H4 \\
\hline Grandes peptídeos (> 7 aminoácidos) & $15,2 \pm 0,9^{\mathrm{d} / 1}$ & $20,2 \pm 2,2^{\mathrm{b} / 2}$ \\
Peptídeos médios (4 a 7 aminoácidos) & $33,7 \pm 1,0^{\mathrm{a} / 2}$ & $36,9 \pm 0,3^{\mathrm{a} / 1}$ \\
Di- e tri-peptídeos & $31,6 \pm 1,1^{\mathrm{b} / 1}$ & $20,6 \pm 1,2^{\mathrm{b} / 2}$ \\
Aminoácidos livres & $79,5 \pm 1,2^{\mathrm{c} / 2}$ & $22,2 \pm 1,0^{\mathrm{b} / 1}$ \\
\hline
\end{tabular}

Todos os valores são apresentados em \% das quatro frações. Os resultados representam a média das triplicatas e seu desvio padrão. Médias indicadas por letras iguais não diferem entre si a 5\% de significância na comparação das diferentes frações de um mesmo hidrolisado. Médias indicadas por números iguais não diferem entre si a 5\% de significância na comparação de uma mesma fração para diferentes hidrolisados. 


\section{CONCLUSÕES}

O emprego da corolase PP possibilitou até 100\% de remoção da Phe de hidrolisados protéicos de arroz pela utilização do carvão ativado, sendo que, dos parâmetros testados, apenas a concentração protéica inicial influenciou na remoção de Phe. Os teores finais de Phe de todos os hidrolisados foram inferiores a 0,1 g/100 g, possibilitando seu uso no preparo de formulações dietéticas para fenilcetonúricos. A concentração protéica inicial de 0,78 e 1,56 g/100 mL foi a que obteve os melhores resultados. O melhor perfil peptídico foi obtido com uma E:S de $1 \%$ e uma concentração protéica inicial de 1,56 g/100 mL.

\section{AGRADECIMENTOS} financeiro.

À CAPES, ao CNPq e à Fapemig, pelo apoio

\section{REFERÊNCIAS BIBLIOGRÁFICAS}

AB ENZYMES. Corolase PP: description and specification. Review Nutrition, [S.1.], n. 2, p. 2, 2001.

AGÊNCIA NACIONAL DE VIGILÂNCIA SANITÁRIA. Resolução RDC n. 360. Aprova Regulamento Técnico sobre rotulagem nutricional de alimentos embalados, tornando obrigatória a rotulagem nutricional. Diário Oficial, Brasília, p. 33, 26 dez. 2003.

AUBES-DUFAU, I.; SERIS, J. L.; COMBES, D. Production of peptic hemoglobin hydrolysates: bitterness demonstration and characterization. Journal of Agricultural and Food Chemistry, Easton, v. 43, n. 8, p. 1982-1988, 1995.

BRASIL. Ministério da Saúde. Portaria n. 847 de 31 de outubro de 2002. Aprova o protocolo clínico e diretrizes terapêuticas - fenilcetonúria - fórmulas de aminoácidos isentas de fenilalanina. Diário Oficial, Brasília, p. 83, 4 nov. 2002.

CARREIRA, R. L.; BARBOSA, C. M. S.; JUNQUEIRA, R. G.; MOTTA, S.; SILVESTRE, M. P. C. Emprego da cromatografia liquida de alta eficiência hidrofílica na determinação dos aminoácidos de hidrolisados de caseína. Ciência e Tecnologia de Alimentos, Campinas, v. 22, n. 3 , p. 229-232, 2002.
CLEMENTE, A. Enzymatic protein hydrolysates in human nutrition. Trends in Food Science \& Technology, Cambridge, v. 11, n. 7, p. 254-262, 2000.

CONNOR, M. A.; SAUNDERS, R. M.; KOHLER, G. O. Rice bran protein concentrates obtained by wet alkaline extraction. Cereal Chemistry, Saint Paul, v. 53, n. 4, p. 488-496, 1976.

DELVIVO, F. M.; MARCO, L. M. de; SILVA, V. D. M.; COELHO, J. V.; SILVESTRE, M. P. C. Uso de carvão ativado e de amberlite xad-4 para remoção de fenilalanina de hidrolisados de soro de leite, obtidos pela ação da pancreatina. Tecno-Lógica, [S.1.], v. 8, n. 2, 2004.

FOOD AND AGRICULTURE ORGANIZATION. Food balance sheet 2004. Rome, 2004. No page.

FRÆKJAER, S. Use of hydrolysates for protein supplementation. Food Technology, Oxford, v. 48, n. 10, p. 86-88, 1994.

GONZÁLEZ-TELLO, P.; CAMACHO, F.; JURADO, E.; PÁEZ, M. P.; GUADIX, E. M. Enzymatic hydrolysis of whey proteins: II. molecular: weight range. BioTechnology \& Bioengineering, [S.1.], v. 44, n. 4, p. 529-532, 1994.

GRANT, A.; BHATTACHARYYA, P. K. Application of derivative spectroscopy to the determination of chromatographic peak purity. Journal of Chromatography, [S.1.], v. 347, p. 219-235, 1985.

ICHIKAWA, T.; TERADA, H. Determination of phenylalanine, tryptophan and tyrosine in a mixture of amino acidas by second derivative spectrophotometry. Chemical Pharmacology Bulletin, New York, v. 29, n. 2, p. 438-444, 1981a.

ICHIKAWA, T.; TERADA, H. Efect of dodecyl sulfate on the spectral properties of phenylalanil residues in serum albumin detected by second derivative spectrophotometry. Biochimica et Biophysica Acta, [S.1.], v. 671, n. 1, p. 33-37, 1981b.

ICHIKAWA, T.; TERADA, H. Estimation of state and amount of phenylalanine residues in proteins by second derivative spectrophotometry. Biochimica et Biophysica Acta, [S.1.], v. 580, n. 1, p. 120-128, 1979. 
ICHIKAWA, T.; TERADA, H. Second derivative spectrophotometry as an effective tool for examining phenylalanine residues in proteins. Biochimica et Biophysica Acta, [S.1.], v. 494, n. 1, p. 267-270, 1977.

INTERNATIONAL RICE RESEARCH INSTITUTE. World rice statistics, 2001. Manila, 2001. No page.

KITAGAWA, T.; OWADA, M.; AOKI, K.; ARAI, S.; OURA, T.; MATSUDA, I.; IGARASHI, Y.; TADA, K.; KATAYAMA, S.; HASHIDA, W. Treatment of phenylketonuria with a formula consisting of low: phenylalanine peptide. Enzime, [S.1.], v. 38, n. 1/4, p. 321327, 1987.

LEVILLAIN, P.; FOMPEYDIE, D. Spectrométrie dérivée: intérêt, limites et applications. Analysis, [S.1.], v. 14, n. 1, p. 1-20, 1986.

LOPES, D. C. F.; DELVIVO, F. M.; SILVESTRE, M. P. C.Use of activated carbon for removing phenylalanine from skim milk powder. Food Science \& Technology, Trivandrum, 2004. In press.

LOPEZ-BAJONERO, L. J.; LARA-CALDERON, P.; GALVEZ-MARISCAL, A.; VELASQUEZ-ARELLANO, A.; LOPEZ-MUNGUIA, A. Enzimatic production of a lowphenilalanine product from skim milk powder and caseinate. Journal of Food Science, Chicago, v. 56, n. 4, p. 938-942, 1991.

MARCO, L. M. de. Uso da papaína imobilizada em carvão ativado e em alumina no preparo de formulações dietéticas para fenilcetonúricos, à base de soro de leite. $2004.99 \mathrm{f}$. Dissertação (Mestrado em Ciência de Alimentos) Universidade Federal de Minas Gerais, Belo Horizonte, 2004.

MICLO, L.; PERRIN, E.; DRIOU, A.; MELLET, M.; LINDEN, G. Determination of the ratios of the aromatic amino acids residues by first-or second-derivative UV spectrometry for a simple characterization of peptides. International Journal of Peptide and Protein Research, [S.1.], v. 46, n. 2, p. 186-192, 1995.

MIRA, N. V. M.; MÁRQUEZ, U. M. L. Importância do diagnóstico e tratamento da fenilcetonúria. Revista de Saúde Pública, São Paulo, v. 34, n. 1, p. 86-96, 2000.
MORAIS, H. A.; MARCO, L. M. de; OLIVEIRA, M. C.; SILVESTRE, M. P. C. Casein hydrolysates using papain: peptide profile and encapsulation in liposomes. Acta Alimentaria, [S.I.], v. 34, n. 1, p. 59-69, 2005.

MORATO, A. F.; CARREIRA, R. L.; JUNQUEIRA, R. G.; SILVESTRE, M. P. C. Optimization of casein hydrolysis for obtaining high contents of small peptides: use of subtilisin and trypsin. Journal of Food Composition and Analysis, San Diego, v. 13, p. 843-857, 2000.

MOSZCZYNSKI, P.; IDZIAC, J. Preparation of enzymatic hydrolysates of casein depleted in phenylalanine. Applied Biochemical Microbiology, [S.1.], v. 29, n. 3, p. 302-306, 1993.

OUTINEN, M. T.; TOSSAVAINEN, O.; HARJU, M.; LINKO, P. Method for removing phenylalanine from proteinaceous compositions, a product so obtained and use thereof. Patents US 5547687, A23J3/34B4; A23J3/34C; A23L1/015E2; A61K38/01B; A61K38/01D6. 12 Sept. 1994; 20 Aug. 1996. Valio Oy, Helsink, Finland, 1996.

PIMENTEL-GOMES, F. Curso de estatística experimental. 14. ed. Piracicaba: ESALQ, 2000. 477 p.

ROJAS, F. S.; OJEDA, C. B.; PAVON, J. M. C. Derivative ultraviolet-visible region absorption spectrophotometry and its analytical applications. Talanta, [S.1.], v. 35, n. 10, p. 753-761, 1998.

SHIMAMURA, S.; TAMURA, Y.; MIYAKAWA, H.; SAITO, H.; KAWAGUCHI, Y.; ISOMURA, N.; AKAZOME, Y.; OCHI, H.; KAWAMOTO, M. Peptide mixture and products thereof. Patents US 5952193, A23C 21/02; A23C 21/04; A23C 21/06; A61K 38/01. 14 Apr. 1997; 14 Sept. 1999. Morinaga Milk, Tokio, Japan, 1999.

SILVA, V. D. M. Uso da pancreatina imobilizada em carvão ativado e em alumina no preparo de formulações sintéticas para fenilcetonúricos, à base de soro de leite. $2004.119 \mathrm{f}$. Dissertação (Mestrado em Ciência de Alimentos) Universidade Federal de Minas Gerais, Belo Horizonte, 2004.

SILVESTRE, M. P. C.; DAUPHIN, C.; HAMON, M. Application of UV absorption and second-derivative spectrophotometry for analysing casein hydrolysates. Analitica Chimica Acta, [S.1.], v. 282, p. 603-612, 1993. 
SILVESTRE, M. P. C.; HAMON, M.; YVON, M. Analyses of protein hydrolysates: I. use of poly (2-hydroxyethylaspartamide)-silica column in size-exclusion chromatography for the fracionation of casein hidrolysates. Journal of Agricultural \& Food Chemistry, Easton, v. 42, n. 12, p. 2778-2782, 1994a.

SILVESTRE, M. P. C.; HAMON, M.; YVON, M. Analyses of protein hydrolysates: II. characterization of casein hydrolysates by a rapid peptide quantification method. Journal Agricultural \& Food Chemistry, Easton, v. 42, n. 12, p. 2783-2789, 1994b.

SOARES, R. L. D.; DELVIVO, F. M.; MARCO, L. M. de; AGUIAR, M. J. B.; JUNQUEIRA, R. G.; FIGUEIREDO, A. F. S.; SILVESTRE, M. P. C. Emprego do carvão ativado para a remoção de fenilalanina de leite em pó. Boletim do Centro de Pesquisa e Processamento de Alimentos, [S.I.], v. 22, n. 1, p. 65-84, 2004.

TAKASE, M.; FUKUWATERI, Y.; KAWASE, K.; KIYOSOWA, I.; OGASA, K.; SUZUKI, S.; KUROUME, T. Antigenicity of casein enzymatic hydrolysate. Journal of Dairy Science, Champaign, v. 62, n. 10, p. 1570-1576, 1979.

ZHAO, Q.; SANNIER, F.; GARREAU, I.; LECOEUR, C.; PIOT, J. M. Reversed-phase high-performance liquid chromatography coupled with second-order derivative spectroscopy for the quantitation of aromatic amino acids in peptides: application to hemorphins. Journal of Chromatography A, [S.1.], v. 723, n. 1, p. 35-41, 1996. 